\title{
Assessment of readiness for the implementation of the hospital health information system under primary health care reorganization in selected hospitals in Kalutara District
}

Rajapaksha DMP, Wickramasinghe SC.

\begin{abstract}
Introduction: Organizational resources and technical structures such as hardware and software are very essential requirements in the redesign of electronic projects. (Ajam, 2011) Before implementation of Hospital Health Information System (HHIS) in primary health care institutions it is essential to conduct an assessment of readiness of institutions.
\end{abstract}

Objective: To assess the readiness for the implementation of Hospital Health Information System under primary health care reorganization in selected Hospitals in Kalutara District.

Methodology: Cross-sectional study was carried out in Divisional Hospitals Bandaragama, Gonaduwa and Haltota. A readiness assessment tool was used to study readiness in Technology and Infrastructure, Human Resources, and Workflow.

Technology and infrastructure readiness and workflow readiness were assessed by interviewing medical officers in charge (MOICs) of relevant three hospitals and by direct observation. For assessment of human resource readiness, a validated and pretested self-administered questionnaire was used for all staff supposed to be involved in the operational process of proposed HHIS in selected hospitals.

Results and discussion: Although all three Hospitals show a total readiness of more than 50\%, technology, infrastructure readiness and workflow readiness of Divisional Hospital Gonaduwa and Haltota are less than $50 \%$. Higher level of Human resource readiness has increased the total readiness of these two hospitals more than 50\%. However, divisional hospital Bandaragama shows more than $50 \%$ readiness of all three types.

Conclusions and recommendations: It is important to have more than $50 \%$ of readiness for all three major sections of the tool individually.

Key words: Readiness assessment, primary Care, Information System

\section{Introduction}

Sri Lankan health sector is heavily dependent on documentation, and it imposes a heavy workload on health care staff as is documentation at present is based almost entirely on handwritten paper records. There is additional work in filling and retrieving information, in copying and summarizing it and transmitting it from one section to another. One of the weaknesses of the health care system is difficulty in tracing records.

Health management information system can reduce the burden of documentation. In addition to reducing documentation an information system can cut down the long queues and provide more time for doctor patient interaction.

Hospital Health Information System (HHIS) is an opensource medical database software planned to be used in primary care settings. It stores clinical details of patients treated and is designed for use mainly by clinical staff. Clinical details are recorded on the system as they examine the patient. The system enables hospital staff to

$>$ Change from more complex paper-based patient management system to more efficient Electronic Health Record System.

$>$ Access patient's medical record anywhere in the country and to share that information among different levels of health care such as primary, secondary and tertiary.

$>$ Conduct disease surveillance and notification easily as patient management system, hospital management system and the disease surveillance and notification systems are integrated with each other.

$>$ Refer previous clinical records when a patient comes for treatment at clinics

$>$ Update and maintain patient's clinical data in each visit.

$>$ Coordinate with laboratory management information system to expand the patient care service by getting investigations done which are not available in primary care institutions but available in secondary and tertiary care hospitals.

$>$ Manage issuing of drugs and monitor the drug stock balance.

The software will thus significantly reduce the need for maintaining paper-based records and enable an improved and efficient service to the patient. 
Although making health records electronically in computer systems has many advantages, establishment of an e- Health information system can also be complicated. The reasons may be unavailability of technology, funding, and lack of personnel with technical and computer skills. Moreover, resistance and opposition to changes from manual systems to electronic systems by some health service providers may create problems.

E-health (Electronic health) readiness assessment, as a part of the assessment prior to implementation aims to evaluate preparedness of each organization component. This process can lead to the correct decision making based on existing realities and constraints of the organization.

\section{General Objective}

To assess the readiness for the implementation of Hospital Health Information System under primary health care reorganization in selected Hospitals in Kalutara District.

\section{Specific Objectives}

1. To assess the following type of readiness for the Hospital Health Information System under primary health care reorganization in selected hospitals in Kalutara District
a. Technology and infrastructure
b. Human Resources
c. Workflow

2. To assess the total / overall readiness for the implementation of Hospital Health Information System under primary health care reorganization in selected hospitals in Kalutara District.

\section{Methodology}

This is a descriptive cross-sectional study conducted in Divisional Hospitals Bandaragama (DHB), Gonaduwa (DHG) and Haltota (DHH).

\section{Figure 1 summarizes the methodology used for the assessment of different types of readiness in the selected Hospitals.}

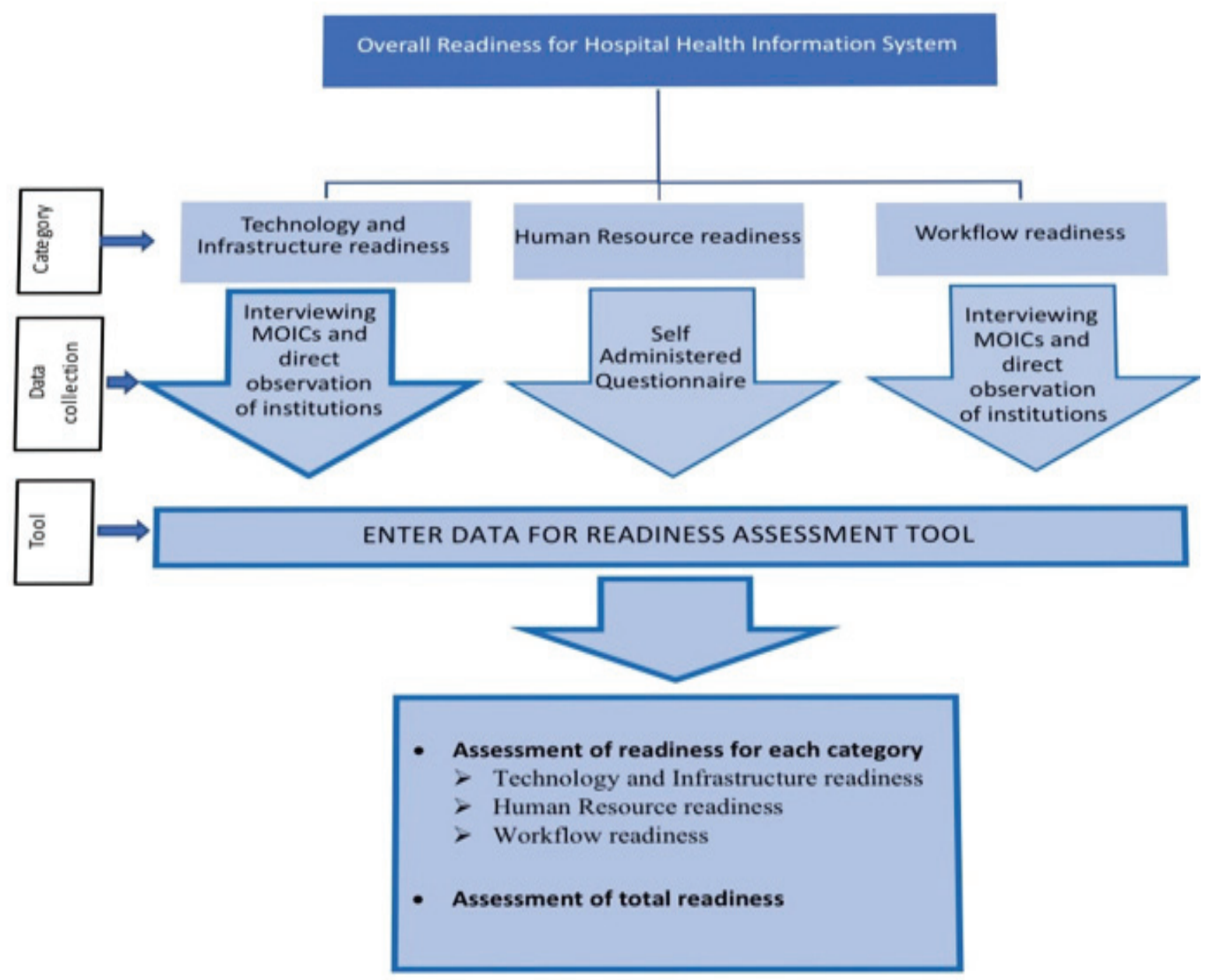


Figure 1: Process of Readiness Assessment in each Hospital

Readiness assessment tool was constructed for the assessment of readiness for implementation of HHIS in the hospitals. Principal Investigator worked with an expert in Information Communication Technology in developing the Readiness assessment tool. This tool has three major components.

1. Technology and Infrastructure readiness

2. Human Resource readiness

3. Workflow readiness

This tool was constructed in English and translated to Sinhala and Tamil languages. Technology and infrastructure readiness is the readiness of the software, hardware, network resources, and services necessary for the implementation, operation, management, and existence of HHIS. Human Resource readiness is the availability of employee skills, talent, and know-how to perform the internal processes critical to the implementation, operation, management, and existence of HHIS. Data was collected through a self-administered Questionnaire (SAQ HS) to complete this category. Workflow readiness is the readiness of the series of activities through which HHIS function from initiation to completion when it is implemented in a healthcare institution.

Out of three sections of the tool, technology and infrastructure readiness and workflow readiness were assessed by interviewing MOICs of relevant three hospitals and by direct observation.

For assessment of Human Resource Readiness, a validated and pretested self-administered questionnaire was administered to all staff supposed to be involved in the operational process of proposed HHIS in selected hospitals.

Principal Investigator (PI) visited all three institutions after obtaining relevant administrative and ethical clearance and himself collected data for the research.

\section{Results}

Assessment of the readiness for the implementation of the New Information System planned for Primary Care Reorganization was done using the tool developed. Table 1 shows the readiness score of selected three hospitals.

Table 1: Readiness Score of Selected Three Hospitals

\begin{tabular}{lrrr}
\hline & $\begin{array}{r}\text { Divisional } \\
\text { Hospital } \\
\text { Bandaragama }\end{array}$ & $\begin{array}{r}\text { Divisional } \\
\text { Hospital } \\
\text { Gonaduwa }\end{array}$ & $\begin{array}{r}\text { Divisional } \\
\text { Hospital } \\
\text { Hultota }\end{array}$ \\
\hline Technology and Infrastructure Readiness & $57.4 \%$ & $42.6 \%$ & $40.7 \%$ \\
Human resource Readiness & $82.7 \%$ & $80.4 \%$ & $82.7 \%$ \\
Workflow Readiness & $54.4 \%$ & $43.8 \%$ & $43.8 \%$ \\
\hline Total Readiness* & $\mathbf{6 3 . 4 7 \%}$ & $\mathbf{5 4 . 2 \%}$ & $\mathbf{5 4 . 8 9 \%}$ \\
\hline
\end{tabular}

* Total readiness was calculated after weighting the three components. Technology and infrastructure readiness:50\%, Human resources readiness: $30 \%$ and workflow readiness:20\%

There is no visible difference among the percentages of Human resource Readiness of three Hospitals and it shows a satisfactory level (Table 1). All three hospitals show a Human Resource Readiness of more than $80 \%$. There is no visible difference of any type of assessed readiness between DHG and DHH. But Technology and Infrastructure readiness and Workflow readiness of DHG and DH Haltota were low.

Table 2 shows readiness score of selected three hospitals after weightage given according to the importance. Weightage was given to each type of readiness as Technology and infrastructure readiness:50\%, Human resources readiness: $30 \%$ and workflow readiness: $20 \%$. 
Table 2: Comparison of each readiness of selected three hospitals after weighting according to the importance.

\begin{tabular}{lrrr}
\hline Section & DHB & DHG & DHH \\
\hline Technology and Infrastructure Readiness (out of 50) & 27.78 & 21.30 & 21.30 \\
Human resource Readiness (out of 30) & 24.82 & 24.13 & 24.82 \\
Workflow Readiness (out of 20) & 10.87 & 8.77 & 8.77 \\
\hline Total & $\mathbf{6 3 . 4 7 \%}$ & $\mathbf{5 4 . 2 0 \%}$ & $\mathbf{5 4 . 8 9 \%}$ \\
\hline
\end{tabular}

DHB has a higher level of total readiness than other two. This is because Technology, Infrastructure and Workflow Readiness were better in DHB. Although the total readiness for all three Hospitals shows more than $50 \%$, Readiness score for Technology, Infrastructure and Workflow of DHG and DHH is less than 50\%. Higher level of Human resource readiness has increased the total readiness percentage of these two hospitals more than $50 \%$.

\section{Discussion}

Lack of readiness weakens the organization to undergo transformation during the implementation of Electronic Health Record Systems. (Ajami, 2011) Sufficient preparedness in an organization enables to custom the system and ensure minimal workflow disruptions and irregularities during and after the implementation of such systems. (Ajami, 2011)

Ajami (2011) explains the requirements associated with electronic readiness and infrastructure readiness. In all three hospitals internet connections were not satisfactory. The download speed was between 4-8 Mbps and connections were shared and limited. Although this is adequate at the moment it needs to be improved before proper establishment of the system. The coverage was limited to some of the essential areas in all three Hospitals. DHB was having both wi-fi and wired internet connections but other two hospitals had only wi-fi connections at the time of the data collection for the study. All three hospitals are having good power backups such as UPS and generators which will activate automatically in any power failure.

Based on the validated assessment tool (Figure 1), majority in the hospital feel that the current paper-based systems in their institutions should be changed with new technology and make it easy for them to work. (DHB$88.6 \%$, DHG-90.0\%, DHH-100\%)

Computer literacy is important in operating Health Information Systems. $42.9 \%$ of relevant staff in DHB is having good computer literacy while another $25.7 \%$ are having adequate knowledge just to manage. In DHB those figures are $20 \%$ and $60 \%$ respectively while in DHH $54.5 \%$ and $27.3 \%$ respectively.
Staff involvement and responsibility held in planning process of Health Information System is not satisfactory. Staff involvement in planning process is important in every organization as the staff are directly involved in the implementation. (Wairimu, 2014)

Majority of the staff accept that the proposed technology is appropriate according to the condition within the Hospital (DHB -85.7\%, DHG -77.8\%, DHH -90.9\%).

Training is definitely the most critical element of the successful implementation and adoption of any technology. Even the best. Electronic Health record is useless unless the staff is trained and comfortable with its capabilities (AFIA, 2019). 71.4\% of Medical Officers in DHB have received proper training for the Hospital Health Information System while it is 50\% in DHG and none of medical officers has received any training for the Health Information System in DH Haltota.

Assessment of the workflow needed for hospital health information system has not been done yet in DHG and DHH. But it has been started in DHB.

\section{Conclusions}

1. Technology and Infrastructure readiness was low in all three selected Hospitals. Only DHB shows Technology and Infrastructure readiness more than $50 \%$ whereas in other two hospitals it was even less than $50 \%$

2. Level of Human resource readiness was satisfactory in all three Hospitals, and it was more than $80 \%$ according to the assessment.

3. Workflow readiness was low in all three Hospitals compared to Human resource readiness. The level of it was more than $50 \%$ only in DHB. In other two Hospitals it was less than $50 \%$.

4. All three Hospitals show a level of total readiness more than $50 \%$. DHB shows a higher value compared to other two Hospitals. Having more than $50 \%$ does not indicate that the institution is ready for the implementation of the HHIS. All three categories should be assessed individually. So, 
according to this study only DHB is ready for the implementation of HHIS.

\section{Recommendations}

1. Readiness assessment should be done in every healthcare institution before the implementation of HHIS to reduce the wastage of resources. The areas with poor level of readiness should be identified and necessary steps should be taken to correct them.

2. Following measures should be taken to improve the Technology and infrastructure readiness.

I. All three Hospitals should be provided with internet connections with a better speed specially with the advancement of the system.

II. Wi-Fi coverage should be expanded to all areas in the hospital before the system proceeds to its next stages.

III. There should be a good trouble shooting system in all three hospitals. Ideally it should be present internally in the institution both for software and hardware.

IV. There should be an external service support with the ability of attending 2 hours.

V. All Hospitals should have a local server to store the data.

3. Awareness programs and training programs should be conducted to improve the Human Resource Readiness.

4. Following measures should be taken to improve the workflow readiness.

I. Assessment of workflow needed for HHIS prior to implementation and redesign should be done when necessary.

II. Protocols should be available in every institution.

III. Identification of barriers should be done and measures must be taken to overcome them

IV. Monitoring and evaluation of all processes should be done.

\section{References}

1. AFIA. (2019). Retrieved from https://afiahealth. com/why-ehr-training-education-is-critical/

2. Ajam, S. (2011). Readiness Assessment of Electronic Health Records Implementation. Retrieved fromACTA INFORM MED: https:// www.ejmanager.com/mnstemps/6/6-1325930921. pdf

3. Ajami, S. (2011). Readiness Assessment of Electronic Health Records Implementation. Retrieved from PMC: https://www.ncbi.nlm.nih. gov/pmc/articles/PMC3564174/
4. Gholamhosseini, L. (2016). The design and application of an e-health readiness assessment toolresearchgate. Retrieved from https://www. researchgate.net/publication/305802695_ The_design_and_application_of_an_e-health_ readiness_assessment_tool

5. Health insite. (n.d.). Retrieved from EHR Selection \& Implementation: https://healthinsight. org/Internal/REC_Event_Resources/Breakout_ Session_1_Readiness_and_Workflow(Track\%20 A).pdf

6. JunhuaLi. (2008). Retrieved from Asis Electronic library: https://aisel.aisnet.org/cgi/viewcontent.cgi ?article $=1020 \&=\&$ context $=$ globdev $2008 \&=\&$ seiredir=1\&referer $=$ https $\% 253 \mathrm{~A} \% 252 \mathrm{~F} \% 252 \mathrm{Fschol}$ ar.google.com $\% 252 \mathrm{Fscholar} \% 253 \mathrm{Fq} \% 253 \mathrm{DReadi}$ ness $\% 252 \mathrm{BAnd} \% 252 \mathrm{Bassessment} \% 252 \mathrm{BAND} \% 2$ 52BE\% 252Bhealth\%252BOR $\% 252$ BElectronic $\%$ 252Bhealth\%2

7. Khoja, S. (n.d.). e-Health readiness assessment tools for healthcare institutions in developing countries. Retrieved from Pub med: https://www. ncbi.nlm.nih.gov/pubmed/17848110

8. PMC. (2012). Retrieved from Iran jurnal of public health: https://www.ncbi.nlm.nih.gov/pmc/articles/ PMC3494230/

9. Readiness for the Networked World. (n.d.). Retrieved from https://cyber.harvard.edu/ readinessguide/

10. S. K. Lwanga and S. Lemeshow. (1991). SAMPLE SIZE DETERMINATION IN HEALTH STUDIES. In S. K. Lemeshow, SAMPLE SIZE DETERMINATION IN HEALTH STUDIES.

11. Salifu. (2017), e-Health readiness assessment factors and measuring tools: A systematic review. Retrieved from International journal of medical informatics: https://www.sciencedirect.com/ science/article/pii/S1386505617302058

12. Sri Lanka: Primary Health Care System Strengthening Project. (2018). Retrieved from The world bank: http://projects.worldbank.org/ P163721?lang=en

13. Wairimu, N. (2014). Factors that influance the leval of staff involvement in the stratergic planning process. Retrieved from JOSR Journal: http:// iosrjournals.org/iosr-jbm/papers/Vol16-issue4/ Version-2/D016422127.pdf 